\title{
MARX E A “RENDA BÁSICA UNIVERSAL”: A IDEIA DE TRANSIÇÃO CAPITALISTA AO COMUNISMO NA FILOSOFIA POLÍTICA DE PHILIPPE VAN PARIJS
}

\author{
MARX AND THE "UNIVERSAL BASIC INCOME": THE IDEA OF \\ CAPITALIST TRANSITION TO COMMUNISM IN THE POLITICAL \\ PHILOSOPHY OF PHILIPPE VAN PARIJS
}

\author{
Ricardo Rojas Fabres*
}

\section{RESUMO}

O trabalho afirma que a preocupação central do projeto marxiano se refere aos mecanismos que separam o homem de sua humanidade - isto é, a ideia de que a atividade capitalista de produção, por meio da alienação, impede o florescimento humano. Assim, considera-se o comunismo, em Marx, como uma forma de organização social baseada no ideal de vida boa enquanto autorrealização coletiva. A partir disso, pretende-se advogar em defesa da compatibilidade entre essas premissas centrais da teoria marxiana e uma proposta radical de justiça distributiva. Nesse sentido, buscaremos relacionar essa perspectiva marxista com a filosofia política de Philippe Van Parijs, especificamente com sua proposta de uma Renda Básica Universal - que consiste em uma renda mínima e incondicional para todos os membros de uma comunidade, independente de trabalho, renda ou contribuição tributária. A tese que será sustentada é que a Renda Básica Universal pode ser concebida como medida para realizar parcialmente os imperativos marxistas em um contexto de escassez moderada.

Palavras-chave: Marxismo, Ética, Distribuição

\begin{abstract}
The paper states that the central concern of the Marxian project refers to the mechanisms that separate man from his humanity - that is, the idea that capitalist production activity through alienation prevents human flourishing. Thus, it is considered communism in Marx, as a form of social organization based on the ideal of the good life as collective self-realization. From this, the article intends to advocate in defense of compatibility between these central tenets of Marxist theory and a radical proposal of distributive justice. In this sense, the article will seek to relate this Marxist perspective with the political philosophy of Philippe Van Parijs, specifically with its proposal for a Basic Income - a minimum and unconditional income for all members of a community, regardless of job, income or tax contribution. The thesis that will be sustained is that the Universal Basic Income can be conceived as a measure to promote partially Marxist imperatives in a context of moderate shortages.
\end{abstract}

Keywords: Marxism, Ethics, Distribution

\footnotetext{
" Colaborador do Observatório de Direitos Humanos (UFPel) e professor-pesquisador da Universidade Aberta do Brasil (UAB), no nível de especialização. Doutorando do Programa de Pós-Graduação em Filosofia da Universidade Federal do Rio Grande do Sul, UFRGS, Brasil. Mestre em Filosofia pela Universidade Federal de Pelotas, UFPEL, Brasil. Graduação em Comunicação Social - Hab. Jornalismo.
} 
El tiempo libre ha sido el acervo de los privilegiados y la cultura ha prosperado en los círculos de la clase dominante.(Gerald Cohen)

\section{Introdução}

O trabalho que segue pretende apresentar argumentos em defesa da tese de que a revitalização do projeto marxista pode estar numa guinada normativa - a partir de uma teoria crítica propositiva em relação às experiências de injustiça e, ao mesmo tempo, orientada para a emancipação humana. Para tal, estrutura-se a partir de duas proposições: i) uma interpretação filosófica do conceito marxiano de comunismo presente na obra do jovem Marx; e ii) a proposta de justiça distributiva elaborada por Philippe Van Parijs. A partir disso será desenvolvido o argumento de que uma "Renda Básica Universal" configura-se como uma possibilidade para realizar parcialmente os imperativos marxistas em um contexto de escassez moderada.

De uma forma geral, do ponto de vista epistemológico, o trabalho situa-se em uma perspectiva que, ao mesmo tempo, critica a modernidade (suas contradições morais, por exemplo) e advoga em defesa de seus imperativos (sua capacidade de fomentar uma sensibilidade política que possibilita a crítica, por outro lado). Manifesta, portanto, uma oposição categórica à agenda teórica que convencionou-se denominar de "pós-moderna" e, além disso, sustenta a prioridade epistemológica e ética da ideia de "dignidade humana". Tomando como ponto de partida essa orientação teórica, o trabalho assume o método materialista e compartilha a reivindicação normativa intrínseca à dignidade humana, supondo que ela não é possível sem uma fundamentação ontológica objetiva.

A partir disso, após apresentar um sucinto panorama do debate normativo no seio do marxismo, discute-se i) como essas considerações estão presentes na obra juvenil de Marx e ii) como essas considerações contribuem para a análise e avaliação moral dos arranjos sociais. No terceiro momento, ao sugerir que a preocupação central de Marx diz respeito ao fim da alienação e ao desenvolvimento de condições concretas para o florescimento humano, são apresentados os argumentos de Van Parijs sobre a "transição capitalista ao comunismo". Por fim à guisa de conclusão, o trabalho procura estabelecer aproximações entre os imperativos marxianos e a filosofia política de Van Parijs - argumentando que a implementação de uma Renda Básica Universal constitui-se como um importante mecanismo para o desenvolvimento de atividades que contribuam para o florescimento humano.

\section{Em torno de uma possível "guinada normativa" na teoria marxista}

A partir da década de 1970, com o previsível declínio da experiência soviética, considerável parcela de autores marxistas passaram a orientar seus interesses para as questões democráticas e de justiça. Naquela altura ainda não se podia falar em uma guinada normativa, pois, a rigor, influenciado pela controversa textura que o tema assume nos textos de Marx, o debate centrava-se, basicamente, em determinar a validade de um componente moral na obra do autor. É claro que nesse caso não estava em questão apenas um preciosismo intelectual, mas a tentativa de refundar, a partir do colapso do "socialismo real", a legitimidade de um projeto emancipatório factível. Essa refundação, sobre a qual não há qualquer consenso, não foi o único fator responsável por conduzir o marxismo a uma reconstrução enquanto tradição teórica. Há de se notar que já nos primeiros anos da década de $1930^{1}$ toda uma geração de intelectuais, influenciados diretamente por György Lukács e Karl Korsch, inaugura um novo paradigma humanista significativamente oposto ao dogmatismo ortodoxo do partido comunista soviético.

No entanto, o que há de específico naquela segunda metade do século XX é o cenário político-econômico de substituição do intervencionismo pelo laissez-faire, fortalecimento do capitalismo e uma profunda ofensiva contra as "utopias" - o que mais tarde se materializaria no discurso apocalíptico pós-moderno. Apesar disso, o acúmulo teórico do marxismo humanista ao longo do século, traduzido em autores como Lukács, Gramsci, Bloch, Lefebrve, Fromm e Marcuse, ainda que não houvesse desenvolvido inte-

\footnotetext{
${ }^{1}$ É nesse período que Lukács e Korsch publicam, em 1923, os textos fundamentais do marxismo ocidental: História e Consciência de Classe e Marxismo e Filosofia. Por consequência, já sob a onda de bolchevização proporcionada pelo $\mathrm{V}$ Congresso da Terceira Internacional, Korsch foi expulso do Partido Comunista Alemão (ANDERSON, 1989) e Lukács conduzido a uma séria de autocríticas após a publicação das obras (BOTTOMORE, 1988).
} 
gralmente uma teoria ética de cunho marxista, a possibilitava a partir do retorno ao jovem Marx. Por isso, quando os intelectuais anglo-saxões, entre eles Gerald Cohen, Joh Roemer, Jon Elster e Philippe Van Parijs, negaram o "hegelianismo excessivo" para rediscutir as categorias marxistas a partir de uma abordagem analítica de caráter normativo, os eurocomunistas já defendiam programaticamente a preservação das liberdades individuais e as instituições políticas da democracia burguesa.

Esse cenário, marcado pela inflexão teórica em torno de uma orientação normativa do Estado e da sociedade civil (cujas primeiras tentativas estão em Lukács e sua reconstrução ontológica da obra marxiana $^{2}$ ), possibilita, ao final da década de 1980 , Gerald Cohen afirmar como urgente para a teoria socialista "identificar os pré-requisitos normativos de uma sociedade igualitária” (CALLINICOS, 2008). Não é estranho, por isso, que no início da década de 1990 Adolfo Sánchez Vázquez tenha defendido que a esquerda, para não renunciar ao socialismo no futuro, deveria fazer "uma política impregnada de um profundo conteúdo moral” (VÁZQUEZ, 1993, p. 76). Apesar disso, o que se percebe desde então, até o final do século XX, é que a teoria social se confrontou com uma ampla hegemonia dos preceitos liberais, especialmente na filosofia política, na qual, via de regra, adota-se o discurso apologético de um capitalismo insuperável.

Por outro lado, em que pese o contexto desfavorável, o marxismo segue exercendo forte influência na crítica social - a julgar pelas tentativas de Cohen em justificar a superioridade moral dos princípios socialistas (em Why Not Socialism?) e a proposta de uma Renda Básica Universal como "via capitalista para o comunismo" (VAN PARIJS, 1988), além do explícito interesse nos textos do jovem Marx por parte dos teóricos comunitaristas e liberais, como Martha Nussbaum, Amartya Sen e Michael Walzer - esse, inclusive, que vê no jovem Marx uma das primeiras

\footnotetext{
${ }^{2}$ Mas também, de forma distinta, no "socialismo ético" dos austro-marxistas. Segundo eles, a realização do socialismo não estaria vinculada a uma classe social - isto é, "todo o ser humano como tal, independente de seus interesses de classe, só podem preservar sua humanidade reconhecendo o valor moral do ideal socialista" (KOLAKOWSKI, 1980, 247).

${ }^{3}$ De uma forma geral, a elaboração ético-antropológica é um tema marcante nos autores da Escola de Budapeste [dentre os quais destacam-se Agnes Heller (Teoria das necessidades em Marx), György Màrkus (Marxismo e Antropologia) e István Mészáros (A teoria da alienação no jovem Marx)].
}

expressões da crítica comunitarista. Ao mesmo tempo, percebe-se uma crescente disposição da filosofia no esclarecimento dos limites morais do atual estágio histórico. Questões como "o que o dinheiro não pode comprar?" (SANDEL, 2012) e "onde começa o inaceitável?” (VAN PARIJS, 2003) parecem complementar os estudos marxistas mais recentes sobre Os limites do capital (HARVEY, 2013) e A crise estrutural do Capital (MÉSZÁROS, 2002).

\section{O jovem Marx e a dialética do florescimento humano}

De uma forma mais abrangente, como já foi discutido em outra oportunidade (Cf. FABRES, 2015) a obra juvenil de Marx pode ser inserida no debate normativo a partir de um movimento dialético do florescimento humano, cuja eticidade reside na excelência humana. Nesse sentido, o núcleo argumentativo do autor deve ser compreendido no percurso concreto entre o salto ontológico (do ser natural para o ser social) e o desenvolvimento pleno das capacidades humanas. Isto é, a arquitetura conceitual elaborada por Marx, tomando como base a particularidade da objetivação humana da natureza, relaciona o processo produtivo com a aquisição de novos poderes, habilidades e necessidades no sentido de maximizar e qualificar o uso da criatividade autenticamente humana.

Assim, numa sociedade humanamente emancipada, segundo Marx, o homem rearticula tanto a sua relação com a natureza quanto sua relação com os outros homens, modificando radicalmente todo o metabolismo social - orientado, agora, não pela ganância e pelo individualismo, mas pelo progresso material e espiritual da coletividade humana. É nesse contexto que a realização progressiva da essência humana corresponde ao "desenvolvimento do homem total, universal" (MARCUSE, 1969, p. 53), de modo que para isso o "homem tem que se emancipar da influência paralisante da especialização" (MARCUSE, 1969, p. 53). Marx ilustra de forma esclarecedora essa questão:

$\mathrm{Na}$ sociedade comunista, onde cada um não tem um campo de atividade exclusivo, mas pode aperfeiçoar-se em todos os ramos que lhe agradam, a sociedade regula a produção geral e me confere, assim, a possibilidade de hoje fazer isto, amanhã aquilo, de caçar pela manhã, pescar à tarde, à noite dedicar-me à criação de gado, criticar após o jantar, 
exatamente de acordo com a minha vontade, sem que eu jamais me torne caçador, pescador, pastorou crítico (MARX, 2007, p. 38).

O comunismo trata-se de um estágio histórico onde as forças produtivas se colocam, consciente e livremente, à disposição da comunidade, visto que nesse caso a atividade produtiva humana não pressupõe a necessidade de recompensas externas, quer dizer, essa se torna responsável por uma experiência universal de autorrealização coletiva. Se nesse ponto podemos atestar a influência aristotélica em Marx, para quem a gênese da ideia de revolução social está em grande parte na contraposição entre a essência do homem e sua condição de vida ${ }^{4}$, há de se destacar, também, que o autor aborda a revolução como uma exigência racional, a ponto de operá-la como um imperativo categórico nos termos kantianos. Como mostra KAIN (1991),

[Para Marx] assim como para Kant, os seres humanos devem ser tratados como fins em si. Todas as instituições que tratam os seres humanos apenas como meio devem ser transformado de uma forma revolucionária. Se esta revolução é realizar o imperativo categórico de que os humanos sejam tratados como fins em si, então a teoria, os ideais filosóficos da filosofia alemã, deve se tornar uma força material (KAIN, 1991, p. 40).

De outro modo, Marx compreende a transformação do capitalismo como um princípio que todos os seres humanos adotariam em condições de exercer sua racionalidade. É também porque identifica a essência humana com o gênero, que Marx pode universalizar suas premissas, dando ênfase, via negação, a exigência racional de conceber o homem como um fim em si e não como um objeto para a realização de interesses individuais [tanto nas ralações de produção, onde o homem é concebido "como animal de trabalho, como uma besta reduzida às mais estritas necessidades corporais" (MARX, 2004, p. 31), quanto nas relações sociais, onde o homem "encara as demais pessoas

\footnotetext{
4 Tampouco se pode negar que a abordagem marxiana, nesse ponto, assemelha-se a tradição do direito natural. KAIN (1991) destaca três pontos que sustentam essa afirmação: (i) a existência de um terreno mora independente capaz de julgar a validade das leis civis; (ii) uma estreita relação entre as leis descritivas da natureza e essas leis como normas sociais prescritivas; (iii) Marx sustenta uma doutrina de essência muito parecida com a de Aristóteles (p. 30). Por outro lado, se fastará dessa tradição ao defender a mutabilidade dessas leis naturais, visto que considera a historicidade um traço característico do ser social.
}

como meios, degrada a si próprio à condição de meio e se torna um joguete na mão de poderes estranhos a ele" (MARX, 2010c, p. 40)]. Como foi visto, essa reivindicação baseia-se na adoção de um valor moral capaz de ser universalizado na forma de um imperativo categórico: a dignidade humana. Por isso, como afirma Mészáros, esse é "o critério que deve ser aplicado a avaliação moral de toda relação humana e não há outros critérios além dele" (2002b, p. 168).

Por outro lado, em que pese o desenvolvimento das capacidades e habilidades individuais (ou seu impedimento) esteja no centro da apreciação ética operada por Marx, sua universalização só é possível ao passo em que o autor descobre na sociabilidade uma determinação essencialmente humana, destacando a coletividade como elemento fundamental do processo de apropriação da essência humana para e pelo homem. A liberdade, desse modo, característica constitutiva do ser do homem, só pode realizada plenamente junto à sua coletividade genérica ${ }^{5}$. Por isso, afirma o autor:

É somente na comunidade [com outros que cada] indivíduo tem os meios de desenvolver suas faculdades em todos os sentidos; somente na comunidade, portanto, a liberdade pessoal torna-se possível [...] Na comunidade real, os indivíduos obtêm simultaneamente sua liberdade na e por meio de sua associação (MARX, 2010c, p. 64).

Essa associação a qual Marx se refere é conscientemente dirigida pela própria comunidade, ao passo em que o ser social reconhece no seus companheiros de interação as mesmas características que o compõe. Por isso, para Marx, assim como para Hegel, a emancipação humana "trata-se da realização da liberdade e eticidade na unidade da vontade individual e geral" (KOWARZIK, 2002, p. 52), no entanto, para o primeiro "essa unidade só pode ser alcançada ali, onde forem suspensas as contradições sociais e as diferenças de classe, gestadas pelo modo capitalista de produção" (KOWARZIK, 2002, p. 52). Assim, o argumento de Marx pode ser reconstruído, do ponto de vista moral, da seguinte forma: Marx herda de Feuerbach a ideia de que o ser humano é um ser na-

\footnotetext{
5 "Uma revolução social se situa do ponto de vista da totalidade porque [...] ela é um protesto do homem contra a vida desumanizada, porque parte do ponto de vista do indivíduo singular real, porque a comunidade, contra cuja separação o indivíduo reage, é a verdadeira comunidade humana, é a essência humana" (MARX, 2010b, p. 76-77)
} 
tural e, ao reconstruir a gênese ontológica desse ser humano, conclui que ele possui uma essência (histórica). Como Aristóteles, Marx supôs que essa essência deve ser realizada progressivamente - de modo que se criem as condições para o florescimento humano. Com base nisso, o autor estabelece um princípio de racionalidade fundamentado ontologicamente e, aproximando-se de Kant, define a revolução social como um imperativo categórico, motivado pelo fato de que (a) o homem deve ser tratado como um fim em si e (b) essa é uma aspiração universal e não de classe.

\section{A ideia de "transição" segundo Van Parijs}

Para fins conceituais, a ideia de transição será compreendida da seguinte forma: (i) Marx apresentou as leis internas do capitalismo, afirmando que tais leis desenvolvem a alienação e impedem o florescimento humano; (ii) Marx profundou em termos sua concepção de comunismo, como "suprassunção positiva da propriedade privada enquanto apropriação da vida humana" (MARX, 2004, p. 106) e, desse modo, abolição da alienação; (iii) o estágio entre o capitalismo (a) e o comunismo (c) foi considerado pelo autor como socialismo - a fase inferior do comunismo (b). Há, portanto, uma ideia de progresso [um movimento que vai de (a) à (c) impulsionado por (b), isto é, que vai do capitalismo para o comunismo impulsionado pelo socialismo]. Significa, portanto, que o comunismo preserva a evolução proporcionada pelo capitalismo e, a partir de suas limitações verificáveis no plano real, o supera dialeticamente. O jovem Marx, desse modo, esclarece que o comunismo só é possível como "evolução", "superação", "progresso" do capitalismo " material e espiritualmente. Assim, nega igualmente qualquer "retorno à simplicidade não natural do ser humano pobre e sem carências que não ultrapassou a propriedade privada e nem mesmo até ela chegou" (MARX, 2004, p. 104).

Do ponto de vista da distribuição de riquezas de uma sociedade, Marx será enfático ao sustentar que no comunismo a distribuição se dará "de cada um segundo suas capacidades, a cada um segundo suas necessidades" (MARX, 2002, p. 33). No socialismo, por sua vez, ao reproduzir distorções inevitáveis do capitalismo, a distribuição ainda se dará conforme a fórmula "a cada qual segundo seu trabalho", visto que "o direito nunca pode ultrapassar a forma econômica e o desenvolvimento cultural, por ela condicionado, da sociedade" (MARX, 2002, p. 33). Desse modo, percebe-se que Marx estabelece um critério distributivo para definir o estágio alcançado por uma sociedade no sentido do comunismo. Dito isso, o que será problematizado aqui, em linhas gerais, é a necessidade do socialismo para a transição mencionada. Ou, retomando os termos utilizados, pretende-se problematizar em que sentido é possível compreender uma transição entre (a) e (c) sem a necessidade de um estágio (b). Segundo Van Parijs,

o socialismo na tradição marxista ortodoxa não se justifica porque seria mais justo que o capitalismo, mas porque era mais eficiente, porque permitia um desenvolvimento mais rápido das forças produtivas e assim realizava mais rapidamente as condições de possibilidade do comunismo, quer dizer, de um Estado da sociedade no qual todos os bens são distribuídos em função das necessidades, e assim cada um fica liberado da compulsão de trabalhar (VAN PARIJS, 2003, p. 18)

De acordo com a interpretação de Van Parijs, o socialismo não seria um requisito para a realização do comunismo e para a abolição da alienação. Para ele, Marx deu bons indícios de que o socialismo pode ser compreendido como meramente instrumental no que diz respeito à abolição da alienação (sendo essa, portanto, a exigência normativa primordial do projeto marxiano). O socialismo, nesse sentido, seria necessário por dois motivos em particular: (i) é um estágio capaz de transformar o ethos da sociedade, de modo que o "homem burguês" seja gradativamente transformado a ponto de conceber o comunismo como uma experiência desejável (VAN PARIJS, 1988, p. 22); (ii) é um estágio que transforma a situação material de escassez que caracteriza o modo capitalista de produção, de modo que o socialismo desenvolve um "estado de abundância requerido para que possa florescer o comunismo” (VAN PARIJS, 1988, p. 22). Disso resulta, na interpretação de Van Parijs, dois pontos: (i) "o comunismo depende do desenvolvimento do altruísmo e da produtividade" (VAN PARIJS, 1988, p. 22); (ii) "tal desenvolvimento se consegue melhor com o socialismo do que com o capitalismo" (VAN PARIJS, 1988, p. 22).

Os dois pontos serão questionados pelo autor. Em relação ao primeiro, Van Parijs (1988) afirma: 
A transição ao comunismo pleno pode então ser concebido como um aumento gradual da parte do produto social distribuído segundo as necessidades frente à parte distribuída de acordo com as contribuições de trabalho. O progresso nessa direção requer que as recompensas materiais percam gradualmente sua importância, mas não implica que os trabalhadores devam estar guiados cada vez mais por motivos altruístas (VAN PARIJS, 1988, p. 23)

$\mathrm{O}$ argumento, nesse caso, afirma que o movimento progressivo no sentido do comunismo possui como núcleo a liberação do trabalho, isto é, o trabalho perde seu status de provedor dos meios de vida para se tornar, nas palavras de Marx, "a primeira necessidade vital” (MARX, 2002, p. 33). Em outras palavras, na base do comunismo está a ideia de que o trabalho gradativamente não seja recompensado externamente. Para isso, no entanto, não seria necessário recorrer ao altruísmo, tampouco a modificação da natureza humana - mas sim transformaria a "natureza do trabalho pago até um ponto em que já não seja distinguível do tempo livre" (VAN PARIJS, 1988, p. 24). Em síntese, segundo o autor, a transição entre (a) e (c) está vinculada à transformação do trabalho enquanto meio de vida (pago) (Tp) em trabalho enquanto necessidade vital (livre) (Tl).

Em relação ao segundo ponto (a produtividade), Van Parijs questiona se o socialismo seria, de fato, mais eficaz do que o capitalismo no que diz respeito ao desenvolvimento das forças materiais da sociedade. Em linhas gerais, o autor demonstra a dificuldade de sustentar a superioridade da economia planificada em relação ao modo como o capitalismo organiza sua força produtiva. Ainda que esse não seja um argumento decisivo, Van Parijs argumenta que seria "eticamente problemático sacrificar um número incalculável de gerações em nome de uma hipotética situação de abundância futura" (VAN PARIJS, 2003, p. 58). Por esse motivo, segundo ele, o mais razoável seria possibilitar que cada geração realize o reino da liberdade no grau mais elevado que possa alcançar (VAN PARIJS, 2002). O autor supõe, assim, que a distinção entre socialismo e capitalismo, nesse caso, pode ser compreendida como "meramente instrumental", de modo que se o socialismo não é um fim e os dois argumentos centrais apresentados por Marx em sua defesa são questionáveis, abre-se espaço para a defesa de um novo modo de transição entre os modos de produção.

\section{Renda Básica Universal: aspectos elementares}

Em linhas gerais, a proposta de uma Renda Básica Universal surge como uma tentativa de responder dois problemas: (i) "Como lutar contra o desemprego nos países ricos sem contar com um crescimento econômico muito acelerado?" e (ii) "Como formular um projeto mobilizador para a esquerda sem abandonar os grandes ideais de emancipatórios e justiça social que motivaram, desde seu início, os movimentos socialistas e as esquerdas do mundo?" (VAN PARIJS, 2002, p.76-77). O resultado disso é uma formulação caracterizada como uma "via capitalista para o comunismo" ou uma "forma elegante de combinar os imperativos de igualdade e eficiência" (VAN DER VEEN e VAN PARIJS, 1987). Em outras palavras, o conceito de Renda Básica Universal (também denominada Renda Básica de Cidadania, Renda Mínima, Basic Income ou Ingreso Ciudadano) resume-se a uma "renda paga por uma comunidade política a todos os seus membros individualmente, independentemente de sua situação financeira ou exigência de trabalho" (VAN PARIJS, 2000, p. 179).

Nesse sentido, as características principais dessa medida são as seguintes: (i) é uma renda paga em dinheiro (ii) por uma comunidade política (iii) para todos os seus membros (iv) individualmente (v) sem verificação da situação financeira e (vi) sem exigência de trabalho (VAN PARIJS, 2000). Desse modo, a RBU possui a particularidade de, diferente de outros tipos de programas sociais, não apresentar qualquer tipo de exigência de renda (como o Bolsa Família) ou trabalho (como os distintos tipos de seguro-desemprego). O resultado, segundo o autor, é que tal medida "dá poder de barganha ao mais fraco de uma maneira que uma renda garantida condicionada ao trabalho não dá" (VAN PARIJS, 2000, p. 192). Em outras palavras: “a não-condicionalidade ao trabalho é um instrumento-chave para impedir que a não-condicionalidade à situação financeira leve à proliferação de empregos desagradáveis" (VAN PARIJS, 2000, p. 192).

A importância desse aspecto, portanto, está diretamente vinculada, como mostra Raventós (2012), ao fato de que assim se desenvolve "uma independência socioeconômica e uma base autônoma de existên- 
cia muito maior que a atual para parte dos cidadãos, sobretudo para aqueles setores mais vulneráveis e dominados" (p.41). Para outros autores, como Iglesias (2001), uma renda deste tipo torna-se um mecanismo de distribuição de renda, "limitando o papel do mercado de trabalho, fonte principal da exploração capitalista na distribuição primária da renda" (p. 45). Desse modo, as pessoas poderão optar conscientemente por um trabalho que não necessite (ou necessite cada vez menos) de recompensas externas - visto que a sobrevivência dessas pessoas não depende da mercantilização da força de trabalho.

De um modo geral, há de se destacar que é parte constitutiva da engenharia econômica do modo capitalista de produção capitalista o fato de que os trabalhadores que não possuem os meios de produção se veem obrigados a vender sua força de trabalho em troca de sua subsistência (CALLINICOS, 2006). O argumento, nesse sentido, é que a transição entre o capitalismo e o comunismo está diretamente relacionada ao modo como a comunidade prioriza as necessidades dos indivíduos. No primeiro estágio, a distribuição das riquezas sociais se dá por meio da quantidade de trabalho exercido, independente das necessidades, enquanto no segundo se dá de acordo com as necessidades, independente de trabalho. Igualmente, o trabalho perde o caráter de "meio de vida" (subsistência) e assume o caráter de "necessidade vital" (espontâneo, livre e criativo).

\section{Aproximações entre a RBU e uma teoria distributiva em Marx}

Marx oferece como chave do materialismo histórico a afirmativa que a classe dominante de cada modo de produção possui seu método particular de extrair o excedente econômico dos produtores diretos. Nos modos de produção que historicamente precedem o capitalismo, a exploração da força de trabalho ocorre por meio de uma coerção extraeconômica, isto é, da utilização explícita da autoridade e da violência. $\mathrm{O}$ capitalismo, por sua vez, ao admitir a propriedade do indivíduo sobre sua força de trabalho não o submete diretamente à violência. Como explica Cohen (1988):

o assalariado é proprietário de sua força de trabalho, não pode ser ameaçado com violentas represálias se se nega a a usá-la, mas dado que necessita dos meios de produção, essa ameaça não é necessária: ele deve firmar um contrato de trabalho, sob pena de morrer de fome (COHEN, 1988, p. 91).

Nesse caso, a manutenção da vida humana está diretamente relacionada à submissão do trabalhador às leis do mercado. Desse modo, como mostra Marx (2004), "o trabalhador tornou-se uma mercadoria e é uma sorte para ele conseguir chegar ao homem que se interesse por ele. E a procura, da qual a vida do trabalhador depende, depende do capricho do rico e capitalista" (MARX, 2004). Assim, dirá Marx, a economia estabelece a proposição de que o trabalhador "tal como todo cavalo tem de receber o suficiente para poder trabalhar" (p. 30), isto é, a economia nacional "conhece o trabalhador apenas como animal de trabalho, como uma besta reduzida às mais estritas necessidades corporais" (p. 32) ao mesmo tempo em que "considera o trabalho abstratamente como uma coisa; o trabalho é uma mercadoria" (p. 35).

Há, desse modo, uma profunda relação de dependência entre o trabalhador e seu "ofício", dado que, desprovido de meios e instrumentos de produção, o indivíduo se vê naturalmente conduzido a ele. Por outro lado, uma proposta radical de distribuição de renda, como uma RBU, melhora a capacidade das pessoas de escolher um trabalho que possibilite uma experiência de autorrealização, ou, em outras palavras, garanta as condições de "eleger os projetos de vida que mais satisfaçam sua ideia de vida boa, sem que sejam afetadas pela chantagem da sobrevivência" (Ramirez, 2003, p. 98). Ou, como aponta Parijs (2000), o trabalhador pode se dedicar a um trabalho que o satisfizesse pessoalmente e não que fosse apenas uma obrigação. Ou seja,

a renda básica reforça de maneira notável a posição de negociação daqueles que se veem obrigados (por não dispor de outro recurso que garanta sua subsistência) a vender sua força de trabalho para sobreviver (RAMOS, p. 101-102)

O trabalho pode converter-se, desta forma, em atividade livre - superando o caráter meramente instrumental criticado por Marx, para quem no capitalismo o trabalho não é voluntário, mas forçado - trabalho obrigatório (2004, p. 83). Como se viu, em Marx há uma condenação moral no que diz respeito ao trabalho enquanto meio de suprir necessidades e não como necessidade primária, vital . Aí reside, portanto, um argumento simpático ao subsídio universal 
que enfrenta a mercantilização da força de trabalho, isto é, que garante que as pessoas tenham suas necessidades vitais garantidas fora do mercado de traba1ho. Desse modo, pode-se argumentar que a abolição da alienação também poderia se realizar mediante a distribuição igualitária dos meios de produção ou da oferta de oportunidades para a execução plena das capacidades humanas, ao mesmo tempo em que se desenvolve uma nova relação entre capital e trabalho. Isso porque, como aponta Gorz (1969),

politicamente, o socialismo não pode ser apenas o poder da classe operária;economicamente, não pode representar simplesmente a propriedade coletiva dos meios de produção, isto é, o término da exploração. Mas é mais que isso:representa também um novo tipo de relação entre os homens, uma nova ordem de prioridades, um novo modelo de vida e de cultura. Se não for tudo isso também, perde seu sentido

A RBU, nesse sentido, reconfigura as relações de produção e as formas de existência de uma comunidade, proporcionando uma analogia com aquilo que Lukács (1979) denomina "salto ontológico" entre o ser natural e o ser natural humano. Tal transformação, segundo o autor, é determinada pela capacidade humana de situar-se para além das necessidades biológicas, idealizando objetivações e suas consequências, numa espécie de "pôr teleológico". Esse conceito, fundamental para qualquer aspiração antropológica de cunho marxista, aqui pode ser resumida simplesmente na seguinte sentença: a capacidade do ser humano em estabelecer determinados fins e os meios para realizá-los. Uma RBU faz com que o indivíduo não utilize o trabalho como meio de satisfação de carência biológicas - como acontece com os animais (MARX, 2004), pois ela assegura a "existência” do indivíduo. A "existência humana" do indivíduo, por outro lado, será reconfigurada a partir das relações individuais e comunitárias, por meio de uma experiência produtiva livre, consciente e geradora de prazeres.

\section{Conclusão}

Nas últimas décadas, a reestruturação produtiva do Capital e a reconfiguração do mundo do trabalho influenciaram profundamente a teoria social marxiana. Com base nesse diagnóstico, o objetivo do trabalho foi analisar, sob uma perspectiva filosófica crítica, possíveis réplicas da teoria aos problemas práticos enfrentados atualmente pela classe-que-vive-do-trabalho (utilizando a expressão de Ricardo Antunes). Para isso, procurou-se compreender as limitações do horizonte liberal/burguês dentro de um arranjo teórico que herda da Teoria Crítica duas premissas básicas: a crítica ao capitalismo e suas formas de dominação e uma orientação radical para a emancipação humana. Desse modo, procurou-se manter fiel a uma condição epistemológica fundamental: a necessidade de buscar, nas condições implícitas da realidade social, o potencial transformador desta própria realidade.

Nesse sentido, a primeira consideração apresentada é que o projeto marxiano baseia-se, essencialmente, em uma preocupação genuína com a dignidade humana e com uma forma de organização (comunista) cujo objetivo é o desenvolvimento pleno das faculdades que constituem essa dignidade. Assim, a desaprovação moral do capitalismo reside no fato de que sua arquitetura social impede a realização desse objetivo - o que potencializa uma série de patologias cuja natureza está vinculada à centralidade ocupada pela alienação na produção e reprodução da vida social. Nesse esquema teórico, compreende-se a superação positiva do capitalismo como algo desejável, possibilitando a reformulação dos fundamentos normativos da teoria marxista.

Apenas num terceiro momento, admitindo a plausibilidade dessa elaboração ética baseada nos textos marxianos, é que propomos a discussão acerca da forma de superação do capitalismo. A sugestão apresentada parte da filosofia política de Philippe Van Parijs, para quem a implementação de uma Renda básica universal constitui-se como um direito dos indivíduos de escolher suas próprias formas de vida. Ao que parece, a referida proposta não inviabiliza a superação do modo capitalista de produção, ainda que contribua para a manutenção imediata de sua hegemonia. O grande mérito da RBU, nesse sentido, é a expansão do direito de escolher, de forma progressiva, todos os aspectos da vida social - o que valoriza profundamente a existência e a autoestima das pessoas e se traduz numa ampliação concreta da noção de liberdade.

\section{Referências}

BOTTOMORE, Tom. Dicionário do pensamento marxista. Rio de Janeiro: Zahar, 1988. 
CALLINICOS, A. Igualdade e capitalismo. In: BORÓN, A; AMADEO, J; GONZÁLEZ, S. (Orgs.). A teoria marxista hoje: problemas e perspectivas. Buenos Aires: CLACSO, 2006. p. 253-269.

COHEN, G. A. "Equality as fact and as norm: reflections on the (partial) demise of marxism." Lua Nova: Revista de Cultura e Política 33, p. 123-134, 1994.

La teoría de la historia de Karl Marx: una defensa. Pablo Iglesias Editorial, 1986.

KAIN, P. J. Marx and Ethics. New York: Oxford University Press, 1991.

KAMENKA, Eugene. The ethical foundations of Marxism. Frederick A. Praeger, 1962.

KOLAKOWSKI, Leszek; RUBIO, Jorge Vigil. Las principales corrientes del marxismo: su nacimiento, desarrollo y disolución. Madrid: Alianza Editorial, 1980.

KOWARZIK, Wolfdietrich Schmied. Práxis e responsabilidade. Porto Alegre: EDIPUCRS, 2002.

MÁRKUS, G. Marxismo y antropología. Barcelona: Grijalbo, 1974.

MARX, Karl. Sobre a questão judaica. São Paulo: Boitempo, 2010.

; ENGELS, Friedrich. A ideologia alemã. São Paulo: Boitempo Editorial, 2007.

; ENGELS, Frederich. Manifesto comunista. São Paulo: Boitempo Editorial, 1998.

. A Sagrada Família. São Paulo: Boitempo, 2003.

. Manuscritos econômico-filosóficos. São Paulo:

Boitempo Editorial, 2004.

Crítica da filosofia do direito de Hegel. São Paulo: Boitempo Editorial, 2005.

MÉSZÁROS, I. Para além do capital. São Paulo: Boitempo Editorial, 2002.

A teoria da alienação em Marx. São Paulo: Boitempo Editorial, 2002b.

RAVENTÓS, D. "¿La renta básica es (o no) justa? Sobre liberalismos y republicanismos". Temas $\mathbf{n}^{\mathbf{0}} \mathbf{7 0}$, p. 39-45, 2012.

VAN PARIJS, P. Marxism recycled. Cambridge: University Press, 1993.

; VAN DER VEEN, P. A. capitalist road to communism. Van Parijs, 1998. p. 155-175.

. Renda básica: renda mínima garantida para o século XXI? Estudos Avançados, v. 14, n. 40, p. 179-210, 2000.
; ARNSPERGER, Christian. Ética econômica e social. São Paulo: Loyola, 2003.

; VANDERBORGHT, Y. Renda básica de cidadania. Editora Record, 2006.

VÁZQUEZ, Adolfo Sanchez. Después del derrumbe: estar o no a la izquierda. Dialéctica, n. 23-24, 1993.

Recebido em: 08-07-2015

Aceito em: 17-09-2015 